\title{
Coding Subtest (WAIS-IV)
}

National Cancer Institute

\section{Source}

National Cancer Institute. Coding Subtest (WAIS-IV). NCI Thesaurus. Code C120363.

A subtest of the Wechsler Adult Intelligence Scale, 4th Edition that is sensitive to brain damage, dementia, age and depression. Using a paper key, the subject copies symbols that are paired with numbers within a specified time limit. 